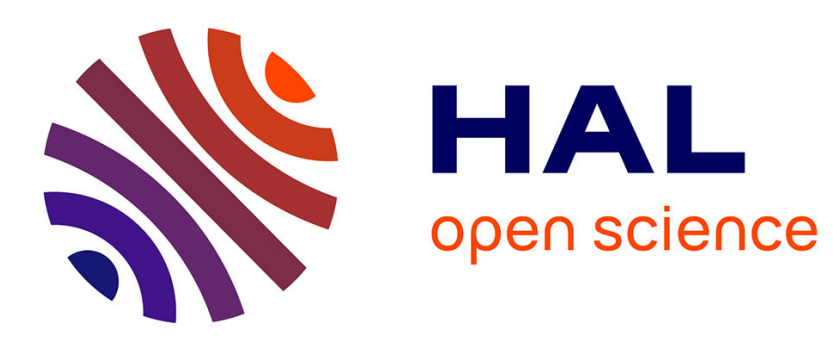

\title{
On the deformation morphology of bulk metallic glasses underneath a Vickers indentation
}

\author{
V. Keryvin, X. D. Vu, V. H. Hoang, Jun Shen
}

\section{To cite this version:}

V. Keryvin, X. D. Vu, V. H. Hoang, Jun Shen. On the deformation morphology of bulk metallic glasses underneath a Vickers indentation. Journal of Alloys and Compounds, 2010, 504 (1), pp.S41S44. 10.1016/j.jallcom.2010.02.073 . hal-00830344

\section{HAL Id: hal-00830344 https://hal.science/hal-00830344}

Submitted on 11 Apr 2014

HAL is a multi-disciplinary open access archive for the deposit and dissemination of scientific research documents, whether they are published or not. The documents may come from teaching and research institutions in France or abroad, or from public or private research centers.
L'archive ouverte pluridisciplinaire HAL, est destinée au dépôt et à la diffusion de documents scientifiques de niveau recherche, publiés ou non, émanant des établissements d'enseignement et de recherche français ou étrangers, des laboratoires publics ou privés. 


\title{
On the deformation morphology of bulk metallic glasses underneath a Vickers indentation
}

\author{
V. Keryvin ${ }^{*, a}$, X.D. Vu ${ }^{\mathrm{a}}$, V.H. Hoang ${ }^{\mathrm{a}}$, J. Shen ${ }^{* *, \mathrm{~b}}$ \\ ${ }^{a}$ LARMAUR ERL CNRS 6274, Université de Rennes 1, Campus de Beaulieu, 35042 Rennes, France \\ ${ }^{b}$ School of Materials Science and Engineering, Harbin Institute of Technology, Harbin 150001, People's Republic of China
}

\begin{abstract}
The techniques commonly used for observing the deformation mechanisms underneath a Vickers indentation in metallic glasses (chemical etching, bonded interface) induce artefacts such as cracks or semi-circular shear-bands. We propose an alternative technique based on the propagation of indentation corner cracks through a pre-existing imprint, which is possible in metallic glasses such as iron-based compositions. With this procedure, only radial shear-bands are observed. Comparisons between the chemical etching or the bonded interface techniques and the new technique are made.
\end{abstract}

Key words: Metallic glasses; amorphous materials; mechanical properties; strain, high pressures; indentation; hardness.

\section{Introduction}

The initiation and propagation stages of plastic flow via shear banding mechanisms are of primary interest for the study of bulk metallic glasses (BMGs) since these plasticity carriers, if arrested or impinged, can promote the ductility these materials usually lack [1]. Indeed, BMGs are brittle in tension and quasi-brittle in compression for most compositions. Therefore plastic mechanisms can not be studied with these uniaxial loadings as the deformation mode is unconstrained. At the contrary, indentation creates a constrained deformation mode where the activation of shear bands will not catastrophically lead to failure. Besides it generates a multi-axial stress state with pressures high enough for the pressure sensitivity of flow to be clearly shown [2]. Shear bands are usually observed around the imprints at the free surface and allow for studying the strain rate sensitivity of their activation and propagation [3] as well as the sensitivity of flow to the normal stress [4-8].

However the picture is not complete as the main areas where plasticity develops are hidden underneath the imprint. For exploring these areas, Donovan [9] used some sectioning, polishing and etching techniques on a Pd-based alloy. She noticed the presence of cracks around and underneath the imprint that were not visible before etching. She concluded that some incipient cracking may be generated during indentation so that the tensile residual stresses may be released by the chemical etching to make these incipient cracks propagate and form fully develop cracking

\footnotetext{
*Corresponding author, e-mail address: vincent.keryvin@univrennes1.fr; tel:+332232357 17; fax: +33223236111.

**Corresponding author, e-mail address: junshen@hit.edu.cn
}

systems. Recently some attention has been put on the deformation mechanisms underneath the imprint by using bonded interface techniques [5, 8, 10-12]. They can bring some insight on the amount of slip in the shear bands, the plastic zone size, the normal stress dependence of flow, the shear band spacing and its spatial strain rate dependence. However, due to the compliance of the bond, out-of-plane displacement is artificially generated so that some features observed shall be considered as artefacts. Consequently, the observation of the true deformation mechanisms underneath the indenter, which are under plane strain conditions, is still an open issue, since for the bonded interface technique plane stress conditions are more likely to exist. The objective of this paper is to propose a novel technique for studying the subsurface mechanism by using a BMG that exhibits indentation cracking features.

\section{Materials and experiments}

The iron-based alloy with a nominal composition of $\mathrm{Fe}_{41} \mathrm{Co}_{7} \mathrm{Cr}_{15} \mathrm{Mo}_{14} \mathrm{C}_{15} \mathrm{~B}_{6} \mathrm{Y}_{2}$ (at.\%) is studied in this paper. The details of its processing and thermal properties can be found in [13] and its mechanical properties in [14].

Deformation mechanisms underneath the indenter are investigated by two different techniques. For the first one, the bonded interface technique, specimens are prepared by bonding two pieces together, already polished to a $1 \mu \mathrm{m}$ finish, then by clamping them in a special device to reduce the bond thickness. Following this, the top surface of the bonded specimen is polished carefully so that the indentation face is flat. Vickers hardness tests are performed on the bonded interface with a $500 \mathrm{~g}$ load. Hardness tests on the interface are conducted, for the Vickers pyramid, in such way that, either the indentation diagonals or the faces 
coincide with the interface, whose thickness is in best cases $20 \mu \mathrm{m}^{1}$. The bonded interface is opened subsequently by dissolving the adhesive in acetone.

A second technique consists in performing a $10 \mathrm{~kg}$ Vickers indentation on a polished surface, thus creating some cracks at the corners of the imprint. The specimen is further broken by bending along these cracks and fracture surfaces are observed. To investigate the subsurface deformation along the faces of the imprint, a two-step procedure is employed. It consists first in performing a 500 $\mathrm{g}$ indentation that generates no cracks [14]. Then another Vickers indentation is made with a higher load $(10 \mathrm{~kg})$ so that the cracks generated at the corners of this new imprint propagate through the low load imprint previously made.

Conical indentations with a $90^{\circ}$ apex angle are also performed for discussing Donovan's work [9]. The observations, at the surface or underneath it, are made by optical microscopy (Olympus BX60F-3, OM) and scanning electron microscopy (Jeol JSM 6301 F, SEM).

\section{Results an discussion}

(Please insert Figure 1 here in full width)

\subsection{Bonded interface technique}

Figure 1 presents the subsurface deformation morphology exhibited by an indentation with corners or faces oriented along the bonded interface. Three different features are to be noticed along the corners. Firstly, we observe the bulge formed by the out-of-plane displacement due to the softness of the bond (Fig. 1.a) [5, 10]. This bulge is all the thicker as we go closer to the free surface where the imprint was made. Secondly, the plastic zone consists in two types of shear-bands (Fig. 1.b and c): the profuse semicircular shear bands that are artefacts due to the release of the constraint in the bond corresponding to out-of-plane shear, and some "radial" 2 cracks that are observed instead of the radial shear bands usually visible in Zr-based alloys $[5,8,10,12]$. It is liable, firstly, that these cracks originate from radial shear-bands, corresponding to in-plane shear, and secondly, that they are artefacts caused by this technique. Indeed, Keryvin et al. [14] showed by a stepwise polishing procedure that no cracks were present underneath the imprint for this particular composition. Finally some cracking features are also visible close to the free surface and they are also artefacts since the load of $500 \mathrm{~g}$ is below the critical load for observing cracks around an imprint for this composition [14]. As for the morphology along and underneath the faces of the imprint (Fig. 1.d), it shows the same two sets of shear-bands observed underneath the

\footnotetext{
${ }^{1}$ Let us notice that it was more difficult to obtain a thinner interface for this iron-based alloy, in comparison to the 1-2 $\mu \mathrm{m}$ interfaces we can obtain in Zr-based compositions [8].

${ }^{2}$ This term is usually reserved for shallow corner cracks [15]
}

corners, with much more semi-circular shear-bands than radial ones. Additional artificially induced cracks are also present near the free surface, in the plastic zone, and even a median crack in the elastic zone.

\subsection{Conical indentation and Donovan's work}

(Please insert Figure 2 here in full width) Figure 2.a presents a $100 \mathrm{~N} 90^{\circ}$ conical imprint. It shows classical cracking features found in brittle materials like silicate glasses or ceramics with median-radial systems (label 1) and chips formed by the intersection of median-radial cracks and lateral cracks (label 2) [15]. The propagation of the latter cracks is clearly visible by watching the arrest lines (label 3) created when the crack hesitates or stops to propagate during indentation [16]. This propagation of lateral cracks is also accompanied by twist hackles (label 4) that are caused by a slight rotation of the crack plane in response to a twist in the axis of principal tension [16]. The median-radial cracks are in remarkable accordance with the cracks observed by Donovan [9] around spherical imprints after chemical etching on a Pd-based glass. This illustrates that tensile stresses at, or close to the free surface, make the cracks propagate during the unloading sequence of indentation [15]. Donovan explained that the chemical etching and these residual tensile stresses were responsible for the propagation of incipient cracks created during indentation. However it is quite unlikely that Pdbased alloys exhibit cracking mechanisms during indentation. Their deformation mechanisms consist only in localised shear-bands with spiral or circular shapes [17, 18], observed also during crack propagation in fracture toughness studies [19]. The high Poisson's ratios of these alloys (more than 0.4 [20]) relate the nature of their chemical bonds, which are very metallic so that the stress is accommodated by shear rather than by bond breaking for more covalent glasses like the iron-based alloy of this study [21]. It is therefore highly liable that the cracking systems Donovan observed were only caused by her chemical etching. This technique is thus not suitable for exploring the deformation mechanisms of BMGs.

\subsection{Bending technique}

Figures 2b-d presents the subsurface features obtained by using the bending technique. Figure $2 \mathrm{~b}$ shows the different deformation and cracking mechanisms obtained after breaking a sample along the corners of an indentation. Apart from the plastic zone (label 1), different regions on the fracture surface are of interest. Regions 2 and 3 are linked to the indentation loading: region 2 to the loading sequence and region 3 to the unloading one [15]. The transition from regions 2 to 3 is spotted by twist hackles. Regions 4 to 6 are connected to the bending loading. Region 4 is the stable crack growth region where the defect (the cracked length at the free surface) is of a size smaller than the critical one for brittle fracture [15]. This critical size reached, unstable fracture occurs (region 5) 
and some other hackles (label 6) are visible. Figure 2c is a magnification on the plastic zone. During bending, the corner cracks propagate also through the plastic zone formed during indentation. Its core, where many shearbands were created, is difficult to describe. Nonetheless, its boundaries exhibit shear-bands. It must be emphasised that, unlike the bonded interface technique that generates profuse semi-circular shear-bands, only radial shear-bands are observed here.

Figure 2d corresponds to the plastic zone along and underneath the faces of an indentation, obtained by making an indentation crack propagate through it. The lateral cracks were generated during this propagation. This time, the whole plastic region is readable, radial shear-bands are easily visible, and, again, no semi-circular shear-bands are observed.

\subsection{Comparisons between the bonded interface and the bending techniques}

A first comparison concerns the plastic deformation size. An index proposed by Ramamurty et al. [5] is the ratio of the distance tip of the imprint-boundary of the plastic zone to the distance free surface-boundary of the plastic zone. The authors reported values of this index of $\sim 0.85$ for a Pd-based alloy. Here we find $\sim 0.77$ and 0.87 respectively for the bonded interface and the bending techniques (faces and corners). The discrepancy may be due to the difference in the alloy composition. Indeed a ratio of $\sim$ 0.82 was found for a Zr-based alloy (unpublished results). Another reason may lie in the presence of cracks for the Fe-based alloy. However for the alloy under investigation, the plastic zone is larger with the bending technique. This seems consistent since all the artificially introduced dissipative mechanisms (semi-circular shear-bands, cracks) by the bonded interface technique should limit the amount of plastic strain inside the radial shear bands and possibly their extent.

A second comparison between these two techniques lies in the intersecting angles of two sets of radial shear-bands. The deviation from $90^{\circ}$ has been put forward by a number of authors [4-7] to be caused by the normal stress dependence of the plastic flow. This angle is $\sim 77^{\circ}$ and $115^{\circ}$ respectively for the bonded interface (Fig. 1c,d) and bending (Fig. 2c,d) techniques. The Mohr-Coulomb friction coefficient $(\mu)$ is computed from the deviation from $90^{\circ}$. It is $13^{\circ}$ for the bonded interface technique and $25^{\circ}$ for the bending technique, that is roughly twice as much as the former, giving $\mu$-values of 0.23 and 0.47 respectively. We do not conclude that the good value of $\mu$ is 0.47 but rather stress on the huge difference in the two values regarding the technique used. This is also very consistent with another work on a Zr-based alloy where, depending on the indenter used, the angle was not constant [8]. We therefore suggest that getting the normal stress dependence of the material by using this angle is a topic that should be more explored.
In summary, the use of the technique described in this paper shall allow to study the deformation mechanisms underneath an imprint in metallic glasses with better confidence than the previously used techniques.

\section{Acknowledgements}

We would like to thank Pr. J.-C. Sangleboeuf, Dr. J.P. Guin and J. Le Lannic (University of Rennes 1, France) for their experimental assistance and for discussions.

\section{References}

[1] C. A. Schuh, T. C. Hufnagel, U. Ramamurty, Acta Mater. 55 (12) (2007) 4067-4109.

[2] V. Keryvin, J. Phys.: Condens. Matter 20 (11) (2008) 114119 (7pp).

[3] W. H. Jiang, M. Atzmon, J. Mater. Res. 18 (4) (2003) 755-757.

[4] C. Tang, Y. Li, K. Zeng, Mater. Sci. Eng. A 304 (2004) 215-223.

[5] U. Ramamurty, S. Jana, Y. Kawamura, K. Chattopadhyay, Acta Mater. 53 (3) (2005) 705-717.

[6] G. R. Trichy, R. O. Scattergood, C. C. Koch, K. L. Murty, Scripta Mater. 53 (2005) 1461.

[7] G. S. Yu, J. G. Lin, M. Moa, X. F. Wang, F. H. Wang, C. E. Wen, Mater. Sci. Eng. A 460-461 (2007) 58-62.

[8] V. Keryvin, R. Crosnier, R. Laniel, V. H. Hoang, J.-C. Sanglebœuf, J. Phys. D: Appl. Phys. 41 (7) (2008) 074029 (7 pp).

[9] P. E. Donovan, J. Mater. Sci. 24 (1989) 523-535.

[10] H. Zhang, X. Jing, G. Subhash, L. J. Kecskes, R. H. Dowding, Acta Mater. 53 (14) (2005) 3849-3859.

[11] R. Bhowmick, R. Raghavan, K. Chattopadhyay, U. Ramamurty, Acta Mater. 54 (16) (2006) 4221-4228.

[12] B.-I. Yoo, J.-I. Jang, J. Phys. D: Appl. Phys. 41 (7) (2008) 074017.

[13] J. Shen, Q. J. Chen, J. F. Sun, H. B. Fan, G. Wang, Appl. Phys. Lett. 86 (15) (2005) 151907.

[14] V. Keryvin, V. H. Hoang, J. Shen, Intermetallics 17 (4) (2009) 211-7.

[15] B. R. Lawn, Fracture of brittle solids, Cambridge University Press, 1993.

[16] G. D. Quinn, Fractography of Ceramics and Glasses, Spec. Pub. 960-16, Nat. Inst. Stand. Technol., Washington, USA, 2007.

[17] V. Keryvin, Acta Mater. 55 (2007) 2565-2578.

[18] V. Keryvin, K. Eswar Prasad, Y. Gueguen, J.-C. Sanglebœuf, U. Ramamurty, Phil. Mag. 88 (12) (2008) 1773-1790.

[19] V. Keryvin, Y. Nadot, Y. Yokoyama, Scripta Mater. 57 (2007) $145-148$.

[20] V. Keryvin, T. Rouxel, M. Huger, L. Charleux, J. Ceram. Soc. Japan 116 (8) (2008) 851-854.

[21] T. Egami, Intermetallics 14 (8-9) (2006) 882-887. 


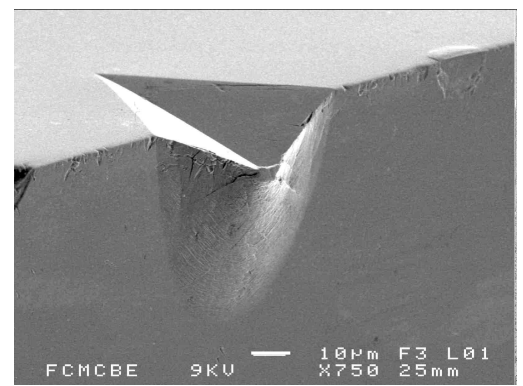

(a)

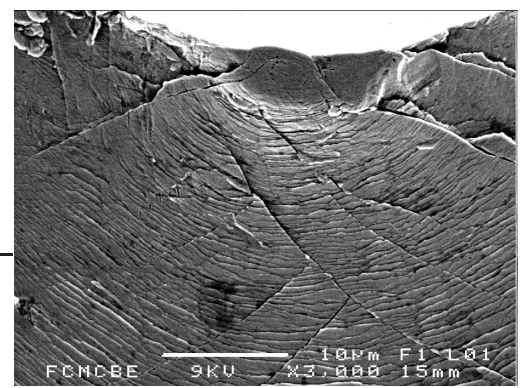

(c)

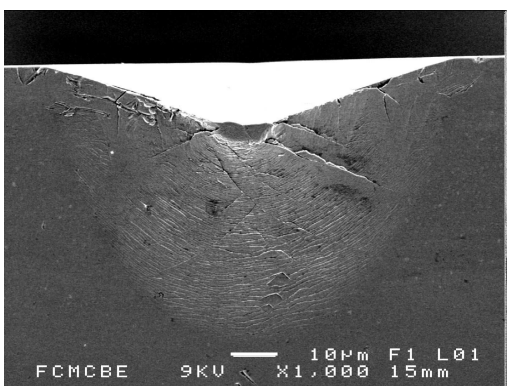

(b)

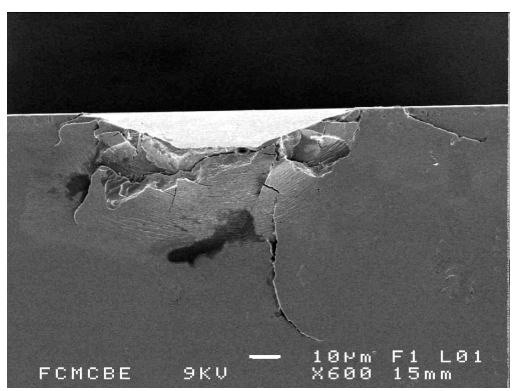

(d)

Figure 1: SEM images of the subsurface morphology of a Vickers indentation obtained by using the bonded interface technique along the corners: (a) lateral view, (b) normal view and higher magnification (c). (d) Normal view by using the technique along the faces of the Vickers indenter.

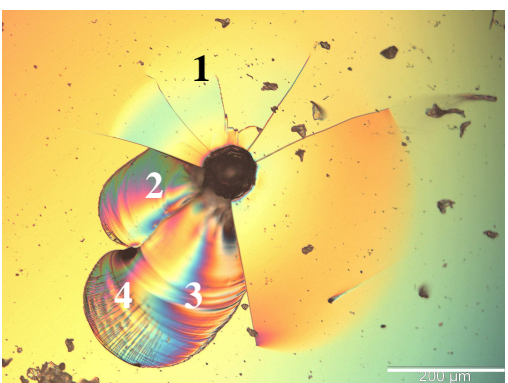

(a)

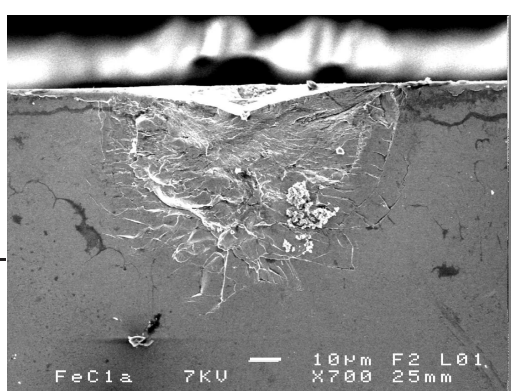

(c)

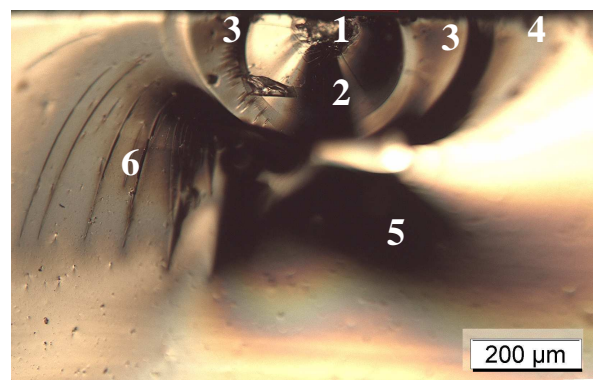

(b)

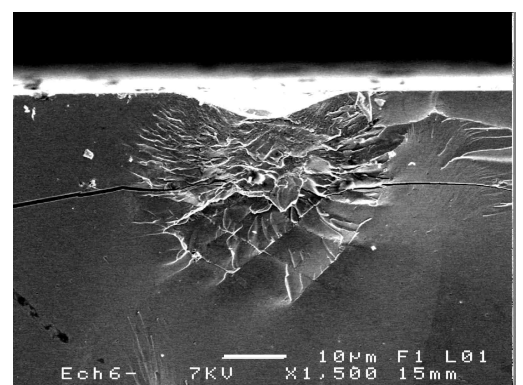

(d)

Figure 2: OM pictures (labels are described in the main text) of (a) a $100 \mathrm{~N} 90^{\circ}$ conical indentation, and (b) the fracture surface of a Vickers indentation broken by bending. SEM images: (c) magnification of (b), and (d) subsurface features obtained by making a indentation crack propagate through the faces of a preexisting crack free imprint. 